\title{
Role of Probiotics in Human Gut Microbiome-Associated Diseases
}

\author{
Seon-Kyun Kim ${ }^{1+}$, Robin B. Guevarra ${ }^{2 \dagger}$, You-Tae Kim ${ }^{1}$, Joongi Kwon ${ }^{1}$, Hyeri Kim², Jae Hyoung Cho ${ }^{2}$, \\ Hyeun Bum Kim ${ }^{2 *}$, and Ju-Hoon Lee ${ }^{1 *}$ \\ ${ }^{1}$ Department of Food Science and Biotechnology, Kyung Hee University, Yongin 17104, Republic of Korea \\ ${ }^{2}$ Department of Animal Resources Science, Dankook University, Cheonan 31116, Republic of Korea
}

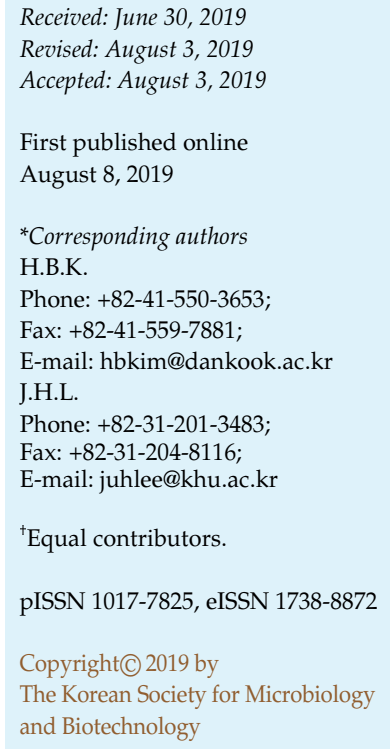

Probiotics, including bacteria and yeast, are live microorganisms that have demonstrated beneficial effects on human health. Recently, probiotic bacteria are constantly being studied and their applications are also being considered in promising adjuvant treatments for various intestinal diseases. Clinical trials and in vivo experiments have extended our current understanding of the important roles that probiotics play in human gut microbiomeassociated diseases. It has been documented through many clinical trials that probiotics could shape the intestinal microbiota leading to potential control of multiple bowel diseases and promotion of overall wellness. In this review, we focused on the relationship between probiotics and the human gut microbiota and its roles in gut microbiome-associated diseases. Here, we also discuss future directions and research areas that need further elucidation in order to better understand the roles of probiotics in the treatment of intestinal diseases.

Keywords: Human gut microbiota, intestinal disease, probiotics

\section{Introduction}

In modern times, probiotics have attracted public interest in the course of promoting human intestinal health, and the addition of prebiotics to probiotics, as synbiotics, has also been recommended. Therefore, the global probiotics market has grown rapidly, which makes probiotics not only as a supplement but also a food [1]. The intake of probiotics has been suggested to enhance overall health and immunity. It is now recognized that the human gut microbiota may play a role in the development of metabolic diseases including obesity, diabetes and inflammatory bowel disease [2]. Interestingly, the administration of probiotics has been shown to improve the prognosis and management of those diseases [3]. In addition, although genomic and microbiological characteristics of individual probiotic strains are important, it is necessary to further understand the effect on human gut microbiota during ingestion. This review provides a brief summary of the concept and function of probiotics, and their relationship with intestinal microbiomeassociated diseases [4].

\section{Concept of Probiotics and Their Potential Benefits}

The Food and Agriculture Organization (FAO) of the United Nations and the World Health Organization (WHO) define probiotics as "live microorganisms which when administered in adequate amounts confer a health benefit on the host." Probiotics are used constantly to improve the homeostasis of internal microbiota to maintain the human intestinal health [5]. Consequently, the number of harmful bacteria that cannot survive in an acidic environment is decreased, and the beneficial bacteria that grow well in an acidic state proliferate, thereby balancing the intestinal microbiota. The relationship among probiotics, gut microbiota, and disease is shown in Fig. 1.

Probiotics are suggested to have both nutritional and 


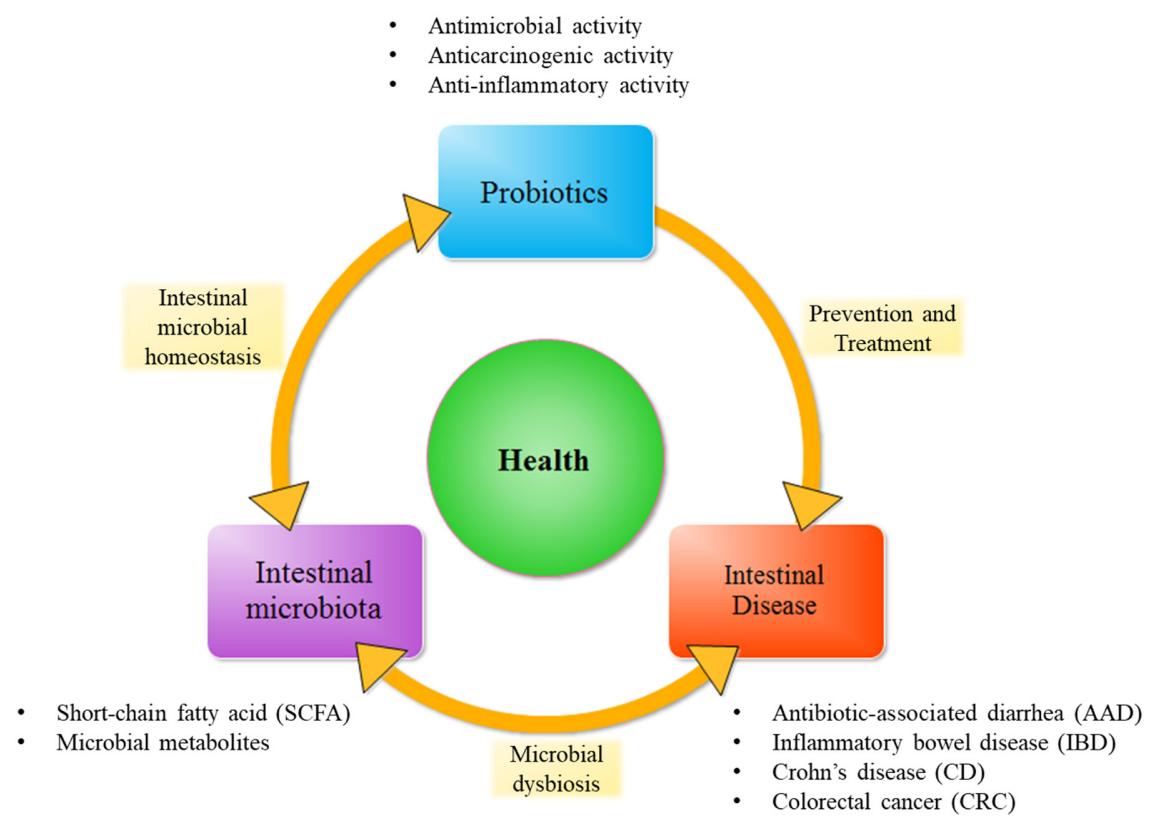

Fig. 1. Role of probiotics relevant to intestinal diseases via recovery of dysbiosis in the intestinal microbiota.

Various intestinal diseases such as AAD, IBD, CD, and CRC are known to be closely associated with dysbiosis of the intestinal microbiota between host-beneficial and host-harmful intestinal bacteria. Once this balanced composition of intestinal microbiota is disrupted, it can cause diarrhea, inflammation, and even colon cancer. Administration of probiotics has been suggested as a therapeutic approach to prevent these intestinal diseases. Probiotics are recognized to have antimicrobial, anti-inflammatory, and even anti-carcinogenic activities, so they may assist in recovering the unbalanced intestinal microbiota. This recovery can also reduce these intestinal diseases or alleviate their symptoms. On the basis of this information, it is now widely believed that there is a strong connection between intestinal microbiota, probiotics, and intestinal health and disease.

beneficial immune modulatory effects in patients with inflammatory bowel disease (IBD). In a previous study, the anti-inflammatory effects of probiotics in patients with IBD revealed that probiotics could have desirable effects resulting in clinical benefits [6]. These health-benefiting effects of probiotics include the prevention of constipation, antibiotic-associated diarrhea (ADD), and enhancement of the immune system $[7,8]$. Because intestinal microbial communities are not permanent and can be altered by various factors such as lifestyle, diet, and antibiotics, probiotics may be used to treat and prevent a variety of intestinal disorders. The beneficial effects of probiotics and their relationship with intestinal diseases have been demonstrated in a variety of studies (Table 1).

\section{The Homeostasis of Human Gut Microbiota and Its Potential Roles in Human Intestinal Health}

The human gut microbiota is composed of complex and diverse microbial communities that are associated with human intestinal health [9]. The gut microbiota is believed to be composed of about 100 trillion microbial cells that provide a wide range of metabolic functions to the host [10]. For example, the intestinal microbiota plays important roles in the degradation of plant-derived complex carbohydrates, which are not digested by the host, due to the lack of enzymes needed to degrade the structural polysaccharides present in plant material [11]. The large intestine contains mostly strict anaerobic bacteria, which can be categorized as either harmful or beneficial [12]. Additionally, the human intestinal microbiota can degrade and produce organic acids and short-chain fatty acids (SCFAs) such as propionate, acetate and butyrate, which have been shown to control the composition of the microbiota. Moreover, human intestinal microbiota are known to perform various functions in the host including intestinal development, homeostasis and protection against pathogenic bacteria. Furthermore, numerous studies have indicated that the dysbiosis of the intestinal microbiota contributes to the development of metabolic diseases including obesity and diabetes, and various intestinal diseases including AAD, IBD, Crohn's disease (CD), 
Table 1. The results of clinical trial between probiotics and disease.

\begin{tabular}{|c|c|c|c|}
\hline Disease & Used probiotics & Study summary & Reference \\
\hline \multirow[t]{3}{*}{$\begin{array}{l}\text { Antibiotic- } \\
\text { associated } \\
\text { diarrhea } \\
\text { (AAD) }\end{array}$} & $\begin{array}{l}\text { L. acidophilus } \\
\text { B. animalis subsp. lactis } \\
\text { L. delbrueckii subsp. bulgaricus } \\
\text { S. thermophilus }\end{array}$ & $\begin{array}{l}\text { Clinical trials on adults (avg. age, 39) who were tested for } 12 \text { days in three } \\
\text { different groups: bio yogurt }(n=131) \text {, commercial yogurt }(\mathrm{N}=118) \text {, and no } \\
\text { yogurt }(\mathrm{N}=120) \text {. The percentages of participants suffering AAD during this } \\
\text { study are } 6.9 \% \text { (bio yogurt), } 11.0 \% \text { (commercial yogurt), and } 14.2 \% \text { (no } \\
\text { yogurt), respectively. }\end{array}$ & [15] \\
\hline & $\begin{array}{l}\text { L. acidophilus } \\
\text { L. delbrueckii subsp. bulgaricus } \\
\text { S. thermophilus }\end{array}$ & $\begin{array}{l}202 \text { seniors (avg. age, } 70 \text { ) volunteered for clinical trials ( } 105 \text { yogurt group and } \\
97 \text { control group) during } 8 \text { days. This study showed that the percentage of } \\
\text { participants suffering AAD was } 12.4 \% \text { in yogurt group and } 23.7 \% \text { in control } \\
\text { group, respectively. }\end{array}$ & [29] \\
\hline & L. rhamnosus GG (LGG) & $\begin{array}{l}188 \text { children (avg. age, } 4 \text { ) participated in a 10-day clinical trial with or } \\
\text { without ingestion of LGG in capsule form. Compared to } 25 \text { children in } \\
\text { control group }(\mathrm{N}=95) \text {, only } 7 \text { children suffered from AAD in LGG group } \\
\text { with higher stool consistency score and lower stool number per day. }\end{array}$ & [16] \\
\hline \multirow[t]{2}{*}{$\begin{array}{l}\text { Inflammatory } \\
\text { bowel disease } \\
\text { (IBD) }\end{array}$} & $\begin{array}{l}\text { L. acidophilus } \mathrm{La}-5 \\
\text { B. animalis subsp. lactis } \mathrm{Bb}-12\end{array}$ & $\begin{array}{l}176 \text { IBD patients ( } 86 \text { in probiotic yogurt group and } 90 \text { in placebo group with } \\
\text { general yogurt) and } 84 \text { healthy people as a control group with probiotic } \\
\text { yogurt volunteered for clinical trials during } 8 \text { weeks. The results showed that } \\
\text { the numbers of Bifidobacterium (B) and Lactobacillus (L) increased in both } \\
\text { probiotic yogurt group (B, } 43.8 \% \text {; } \mathrm{L}, 36.1 \% \text { ) and control group (B, } 11.0 \% \text {; } \mathrm{L} \text {, } \\
16.2 \%) \text {, comparing to placebo group (B, }-4.3 \% \text {; } \mathrm{L}, 3.3 \%) \text {. }\end{array}$ & [18] \\
\hline & $\begin{array}{l}\text { B. longum With } \\
\text { fructooligosaccharide/inulin } \\
\text { mixture for synbiotics }\end{array}$ & $\begin{array}{l}16 \text { IBD patients (avg. age, } 43) \text { were tested for } 4 \text { weeks with two different } \\
\text { groups: synbiotic group }(n=8) \text { and placebo group }(n=8) \text {. mRNA levels of } \\
\text { inflammatory cytokines (TNF- } \alpha \text { and IL-1 } \alpha \text { ) were significantly reduced and } \\
\text { subsequent biopsies in the test group confirmed reduction of inflammation. }\end{array}$ & [20] \\
\hline $\begin{array}{l}\text { Crohn's } \\
\text { disease (CD) }\end{array}$ & $\begin{array}{l}\text { L. rhamnosus NCIMB } 30174 \\
\text { L. plantarum NCIMB } 30173 \\
\text { L. acidophilus NCIMB } 30175 \\
\text { E. faecium NCIMB } 30176\end{array}$ & $\begin{array}{l}62 \mathrm{CD} \text { patients volunteered for } 4 \text { weeks as probiotic group }(\mathrm{N}=33) \text { and } \\
\text { placebo group }(\mathrm{N}=29) \text {. However, there was no significant statistical } \\
\text { difference between the two groups and inflammation reduction was not } \\
\text { observed. }\end{array}$ & [17] \\
\hline $\begin{array}{l}\text { Crohn's } \\
\text { disease }(C D) \\
\text { continued }\end{array}$ & $\begin{array}{l}\text { VSL\#3 } \\
\text { (Lactobacillus, Bifidobacterium, } \\
\text { S. thermophilus) }\end{array}$ & $\begin{array}{l}119 \text { CD patients were tested for } 1 \text { year as VSL\# group }(\mathrm{N}=59) \text { and placebo } \\
\text { group }(\mathrm{N}=60) \text {. VSL\#3 group was divided into three subgroups: a screening } \\
\text { phage (Day 0), a double-blind treatment phase (Day 1-90), and an open-label } \\
\text { treatment phase (Day 91-365). While late VSL\#3 group (open-label treatment } \\
\text { phase, Day 91-365) showed } 42.1 \% \text { severe recurrence, early VSL\#3 group (Day } \\
\text { 1-365) showed only } 20.5 \% \text { severe recurrence. All CD patients receiving VSL\#3 } \\
\text { showed reduced mucosal inflammatory cytokine levels, comparing to the } \\
\text { placebo group. }\end{array}$ & [23] \\
\hline \multirow[t]{2}{*}{$\begin{array}{l}\text { Colorectal } \\
\text { cancer (CRC) }\end{array}$} & $\begin{array}{l}\text { L. paracasei } \\
\text { Leu. mesenteroides } \\
\text { L. plantarum } \\
\text { P. pentosaceus with prebiotic } \\
\text { mixture (betaglucan, inulin, } \\
\text { pectin, and resistant starch) } \\
\text { for synbiotics }\end{array}$ & $\begin{array}{l}54 \text { CRC patients (avg. age, } 64 \text { ) were tested for three days before surgery in } \\
\text { three groups: group A (synbiotics), B (prebiotics) and C (placebo with bowel } \\
\text { preparation). Quantitative Real-Time PCR showed that L. paracasei was } \\
\text { detected with the highest number in group A ( } 53.8 \text {-fold), comparing to } \\
\text { groups B ( } 2.5 \text {-fold) and C. However, Leuconostoc mesenteroides, P. pentosaceus, } \\
\text { and L. plantarum were not detected in group B and C, and was only detected } \\
\text { with high number in group A. }\end{array}$ & [27] \\
\hline & $\begin{array}{l}\text { B. longum } \\
\text { L. acidophilus } \\
\text { E. faecalis }\end{array}$ & $\begin{array}{l}60 \text { CRC patients were tested for } 12 \text { days in a probiotics group }(\mathrm{N}=30) \text { and a } \\
\text { placebo group }(\mathrm{N}=30) \text {. The incidence of diarrhea was significantly lower in } \\
\text { the probiotics group }(26.67 \%, 8 / 30) \text { than in the placebo group }(53.33 \%, 16 / 30) \text {. }\end{array}$ & [30] \\
\hline
\end{tabular}

ulcerative colitis (UC), and colorectal cancer (CRC) [3, 13].

A well-balanced (homeostatic) gut microbial population is essential for the host and the microbiota to coexist in a mutually beneficial relationship. Failure to maintain gut homeostasis leads to negative changes in the host metabolism which are linked to chronic diseases such as IBD, cancer, cardiovascular disease and metabolic syndrome [14]. It has been recognized that imbalance of the 
microbiota also plays a role in the development of asthma [15]. Therefore, various factors involved in the regulation of the gut microbiome are key in the prevention and treatment of diseases.

\section{Human Gut Microbiome-Associated Diseases and Probiotics Applications}

\section{Dysbiosis of the Human Gut Microbiota}

Microbial dysbiosis is defined as the imbalance of the structure and function of the gut intestinal microbiota [16]. It is a common problem in the current era, caused by bacterial infections, changes in diet, and antibiotics. Recent research has demonstrated that dysbiosis of the gut microbiota is associated with the pathogenesis of intestinal disorders such as IBD, irritable bowel syndrome (IBS) and coeliac disease. Beneficial bacteria in the intestinal tract inhibit infiltration and growth of pathogenic bacteria via their competition for space and resources [17]. Interestingly, probiotics are one of the key solutions to restore the gut microbial balance and to prevent infections in patients following antibiotic treatment, which induces gut microbiota dysbiosis.

\section{Antibiotic-Associated Diarrhea (AAD)}

AAD is a common adverse effect of antibiotic treatment, which results from the disruption of the intestinal microbiota. One of the causes of AAD is a disease-causing bacterium, Clostridioides (formerly Clostridium) difficile, that can cause infection of the large intestine as a result of reduced resistance to antibiotics [18]. Interestingly, it has been suggested that probiotics may be beneficial and safe in the prevention of AAD as demonstrated in several randomized controlled trials (RCT). For example, Goldenberg et al. reported that probiotics are effective in the prevention of C. difficile-associated diarrhea in adults and children [19, 20]. A previous review and meta-analysis suggested that the protective effects of probiotics as adjunct therapy may be used in the prevention of AAD in outpatients of all ages [18]. In this study, it has been reported that probiotic intervention may reduce the risk of AAD by $51 \%$ with no apparent increase in the risk of side effects [18]. Moreover, combined results in various trials showed that Lactobacillus rhamnosus and Saccharomyces boulardii were the most protective against AAD. Further clinical trials for ADD are summarized in Table 1. However, the exact cause of AAD has not yet been determined, thus further studies are needed to elucidate the underlying mechanisms of AAD as caused by bacterial infection.

\section{Inflammatory Bowel Disease (IBD)}

IBD is a chronic inflammatory disease of the gastrointestinal tract. IBD encompasses Crohn's disease (CD), ulcerative colitis (UC) and indeterminate colitis (IC), which can be differentiated by the location of the inflammation in the gastrointestinal (GI) tract [21]. Although the cause of IBD is not yet well understood, it is thought to be an abnormal reaction of the body's immune system. Unbalanced diet and stress are considered to be potential factors for IBD. Some evidence suggests that intestinal microbiota may be involved in the pathogenesis of IBD. Furthermore, a number of studies have revealed the difference in the composition of the microbiota between healthy individuals and IBD patients [22]. It has also been suggested that maintaining the balance of intestinal microbiota may be important in preventing IBD [23]. In the past decades, probiotics have gained much attention as a potential therapy to modulate the microbiota and its beneficial effects in IBD. For example, probiotics were used for inducing remission and maintenance therapy in ulcerative colitis [24]. However, a recent study indicated that probiotic supplementation in patients with inflammatory bowel disease is a promising adjuvant treatment in UC but not in CD [21]. Therefore, there is still insufficient data available regarding the efficacy of probiotics to provide generalized recommendations for use in patients with $C D$.

\section{Crohn's Disease (CD)}

$C D$ is an inflammatory bowel disease that affects the entire GIT, which is accompanied by symptoms such as abdominal pain, diarrhea, fever, fatigue, and weight loss. Although the cause of CD is still unknown, it has been hypothesized that various factors such as microbiological, genetic and environmental factors play a role in the development of CD [25]. There is no definite cure yet for $\mathrm{CD}$, but there are several ways to alleviate the symptoms. For example, steroid medications may be used to reduce intestinal inflammation, and immunosuppressants may be taken to reduce the activity of the immune system [26]. Similarly, probiotics may offer an alternative approach in addition to conventional therapy. For example, Fedorak $e t$ al. demonstrated that supplementation of probiotics in $C D$ patients was beneficial after surgery as compared with the late supplementation [27]. However, another recent study demonstrated that multi-strain probiotic adjuvant treatment had no significant changes in intestinal inflammation following the probiotic therapy in patients with CD [21]. Therefore, due to inconsistencies in the results of clinical trials involving probiotic supplementation in the treatment 
of $C D$, further research is needed to identify the roles of probiotics.

\section{Colorectal Cancer (CRC)}

$\mathrm{CRC}$, also known as bowel cancer or colon cancer, is a cancer in any part of the large intestine including the colon or rectum. The incidence rate of colon cancer has been increasing in developed countries such as Europe, the United States, and Australia [28]. Symptoms of the disease include bloody excrement and weight loss. It is mostly caused by aging, lifestyle, but genetic cases are few. However, in developing countries where regular health screening is not possible, the incidence of colon cancer in young people is high [23]. Moreover, people with inflammatory bowel disease such as UC or CD have an increased risk of developing colorectal cancer [29]. Interestingly, recent studies have explored the roles of probiotics in the prevention of colorectal cancer through alteration of the intestinal microbiota and its possible immunomodulatory mechanisms. However, the effectiveness of cancer therapy using probiotics warrants further investigations including clinical trials and animal model studies since not all probiotics have the same effects [30].

Even though the effectiveness of probiotics has been proven through a great many clinical studies as well as animal experiments, much remains to be learned. The study of clinical trials showed that the intake of synbiotics resulted in a significant change in intestinal microbiota in colorectal cancer patients, with an increase in Lactobacillus [31]. In some patients who underwent colonic resection, improvement of mucosal structure in the way of better of epithelial barrier function was confirmed. Therefore, ingestion of synbiotics may also alter the metabolic activity in the intestines. These findings suggest that probiotics are effective not only in animals but also in humans in the treatment and prevention of intestinal disorders such as colorectal cancer [14].

\section{Future Prospects}

Previous studies evaluated human intestinal microbiota following ingestion of probiotics have shown promising results to treat human gut microbiome-associated diseases. In addition, studies to identify and evaluate the roles of probiotics in human gut diseases have become more intense in recent years. Even though there are still a variety of hypothesis driven studies needed, previous studies as well as on going ones indicate that probiotics can be used as potential solutions to prevent or treat human gut microbiome-associated diseases. According to rapid development of NGS technologies, omics studies of the selected probiotics, probably associated with homeostasis of human gut microbiota and even regulation of intestinal diseases, have been recently made available to further understand their effects for maintenance and promotion of human health. These various omics technologies including microbial genomics, transcriptomics, metagenomics, and even metabolomics have extended our knowledge on isolation and selection of new probiotic strains, verification of their real probiotic effects and even molecular mechanisms, and evaluation of their health-promoting effects in in vitro as well as in vivo experiments. Therefore, this extended information of probiotics and their effects on human health on an omics level would be an essential key in the development of new probiotics as well as even pharmabiotics. However, overuse of specific probiotics such as L. rhamnosus has been reported to cause bacteremia, sepsis, or endocarditis in patients with severe inflammations in digestive organs [32]. Therefore, it is important to use proper amounts of probiotics when they are used on specific patients for a therapeutic purpose.

\section{Acknowledgments}

The present study was supported by the research fund (19162MFDS037) from the Ministry of Food and Drug Safety, Republic of Korea. This research was also supported by Kyung Hee University in the sabbatical year of 2018 for J-H. Lee.

\section{Conflict of Interest}

The authors have no financial conflicts of interest to declare.

\section{References}

1. de Simone C. 2018. The unregulated probiotic market. Clin. Gastroenterol. H. 17: 809-817

2. Choi S, Hwang Y-J, Shin M-J, Yi H. 2017. Difference in the gut microbiome between Ovariectomy-induced obesity and diet-induced obesity. J. Microbiol. Biotechnol. 27: 2228-2236.

3. Qin J, Li R, Raes J, Arumugam M, Burgdorf KS, Manichanh C, et al. 2010. A human gut microbial gene catalogue established by metagenomic sequencing. Nature 464: 59-65.

4. Wang W, Xing W, Wei S, Gao Q, Wei X, Shi L, et al. 2018. Semi-rational screening of the probiotics from the fecal flora of healthy adults against DSS-induced colitis mice by 
enhancing anti-inflammatory activity and modulating the gut microbiota. J. Microbiol. Biotechnol. [Epub ahead of print]

5. Sanders ME, Heimbach JT, Pot B, Tancredi DJ, LenoirWijnkoop I, Lähteenmäki-Uutela A, et al. 2011. Health claims substantiation for probiotic and prebiotic products. Gut Microbes 2: 127-133.

6. Lorea Baroja M, Kirjavainen P, Hekmat S, Reid G. 2007. Anti-inflammatory effects of probiotic yogurt in inflammatory bowel disease patients. Clin. Exp. Immunol. 149: 470-479.

7. Cremonini F, Di Caro S, Nista EC, Bartolozzi F, Capelli G, Gasbarrini G, et al. 2002. Meta-analysis: the effect of probiotic administration on antibiotic-associated diarrhoea. Aliment. Pharmacol. Ther. 16: 1461-1467.

8. Bae J-Y, Kim JI, Park S, Yoo K, Kim I-H, Joo W, et al. 2018. Effects of Lactobacillus plantarum and Leuconostoc mesenteroides Probiotics on Human Seasonal and Avian Influenza Viruses. J. Microbiol. Biotechnol. 28: 893-901.

9. Clemente JC, Ursell LK, Parfrey LW, Knight R. 2012. The impact of the gut microbiota on human health: an integrative view. Cell 148: 1258-1270.

10. Ley RE, Peterson DA, Gordon JI. 2006. Ecological and evolutionary forces shaping microbial diversity in the human intestine. Cell 124: 837-848.

11. Flint HJ, Scott KP, Duncan SH, Louis P, Forano E. 2012. Microbial degradation of complex carbohydrates in the gut. Gut Microbes 3: 289-306.

12. Apajalahti J. 2005. Comparative gut microflora, metabolic challenges, and potential opportunities. J. Appl. Poultry Res. 14: $444-453$.

13. Wen H, Yin X, Yuan Z, Wang X, Su S. 2018. Comparative Analysis of Gut Microbial Communities in Children under 5 Years Old with Diarrhea. J. Microbiol. Biotechnol. 28: 652-662.

14. Marteau P, Seksik P, Jian R. 2002. Probiotics and intestinal health effects: a clinical perspective. Br. J. Nutr. 88: S51-S57.

15. Hilty M, Burke C, Pedro H, Cardenas P, Bush A, Bossley C, et al. 2010. Disordered microbial communities in asthmatic airways. PLoS One 5(1): e8578.

16. Carding S, Verbeke K, Vipond DT, Corfe BM, Owen LJ. 2015. Dysbiosis of the gut microbiota in disease. Microb. Ecol. Health Dis. 26: 26191.

17. Ouwehand A, Kirjavainen P, Grönlund M-M, Isolauri E, Salminen S. 1999. Adhesion of probiotic micro-organisms to intestinal mucus. Int. Dairy J. 9: 623-630.

18. Blaabjerg S, Artzi DM, Aabenhus R. 2017. Probiotics for the Prevention of Antibiotic-Associated Diarrhea in OutpatientsA Systematic Review and Meta-Analysis. Antibiotics. 6(4). pii: E21.

19. Conway S, Hart A, Clark A, Harvey I. 2007. Does eating yogurt prevent antibiotic-associated diarrhoea?: A placebocontrolled randomised controlled trial in general practice. Br. J. Gen. Pract. 57: 953-959.

20. Vanderhoof JA, Whitney DB, Antonson DL, Hanner TL, Lupo JV, Young RJ. 1999. Lactobacillus GG in the prevention of antibiotic-associated diarrhea in children. J. Pediatr. 135: 564-568.

21. Bjarnason I, Sission G, Hayee B. 2019. A randomised, double-blind, placebo-controlled trial of a multi-strain probiotic in patients with asymptomatic ulcerative colitis and Crohn's disease. Inflammopharmacology 27: 465-473.

22. Shadnoush M, Hosseini RS, Khalilnezhad A, Navai L, Goudarzi H, Vaezjalali M. 2015. Effects of Probiotics on Gut Microbiota in Patients with Inflammatory Bowel Disease: A Double-blind, Placebo-controlled Clinical Trial. Korean J. Gastroenterol. 65: 215-221.

23. Yang J, Yu J. 2018. The association of diet, gut microbiota and colorectal cancer: what we eat may imply what we get. Protein Cell 9: 474-487.

24. Furrie E, Macfarlane S, Kennedy A, Cummings J, Walsh S, O'Neil D, et al. 2005. Synbiotic therapy (Bifidobacterium longum/Synergy 1) initiates resolution of inflammation in patients with active ulcerative colitis: a randomised controlled pilot trial. Gut 54: 242-249.

25. Baumgart DC, Carding SR. 2007. Inflammatory bowel disease: cause and immunobiology. Lancet 369: 1627-1640.

26. Cowan DC, Cowan JO, Palmay R, Williamson A, Taylor DR. 2010. Effects of steroid therapy on inflammatory cell subtypes in asthma. Thorax 65: 384-390.

27. Fedorak RN, Feagan BG, Hotte N, Leddin D, Dieleman LA, Petrunia DM, et al. 2015. The probiotic VSL\#3 has antiinflammatory effects and could reduce endoscopic recurrence after surgery for Crohn's disease. Clin. Gastroenterol. Hepatol. 13: 928-935.

28. Center MM, Jemal A, Smith RA, Ward E. 2009. Worldwide variations in colorectal cancer. CA Cancer J. Clin. 59: 366-378.

29. Triantafillidis JK, Nasioulas G, Kosmidis PA. 2009. Colorectal cancer and inflammatory bowel disease: epidemiology, risk factors, mechanisms of carcinogenesis and prevention strategies. Anticancer Res. 29: 2727-2737.

30. Liong M-T. 2008. Roles of probiotics and prebiotics in colon cancer prevention: postulated mechanisms and in-vivo evidence. Int. J. Mol. Sci. 9: 854-863.

31. Krebs B. 2016. Prebiotic and Synbiotic treatment before colorectal surgery-randomised double blind trial. Coll. Antropol. 40: 35-40.

32. Boyle, R. J., Robins-Browne, R. M., \& Tang, M. L. 2006. Probiotic use in clinical practice: what are the risks?. Am. J. Clin. Nutr. 83: 1256-1264.

33. Beniwal RS, Arena VC, Thomas L, Narla S, Imperiale TF, Chaudhry RA, et al. 2003. A randomized trial of yogurt for prevention of antibiotic-associated diarrhea. Dig. Dis. Sci. 48: 2077-2082.

34. Yang Y, Xia Y, Chen H, Hong L, Feng J, Yang J, et al. 2016. The effect of perioperative probiotics treatment for colorectal cancer: short-term outcomes of a randomized controlled trial. Oncotarget 7: 8432-8440. 